\title{
DEFECT SELECTIVE ETCHING OF THICK AIN LAYERS GROWN ON 6H-SIC SEEDS - A TRANSMISSION ELECTRON MICROSCOPY STUDY
}

Luke Owuor Nyakiti ${ }^{1}$, Jharna Chaudhuri ${ }^{2}$, Ed A Kenik ${ }^{3}$, Peng Lu ${ }^{4}$, and James H Edgar ${ }^{4}$

${ }^{1}$ Department of Mechanical Engineering, Texas Tech University, 7th Street \& Boston, Lubbock, TX, 79409-1021

${ }^{2}$ Mechanical Engineering, Texas Tech University, 7th Street \& Boston Avenue, Lubbock, TX, 79409-1021

${ }^{3}$ Oak Ridge National Laboratory, 1 Bethel Valley Road, Oak Ridge, TN, 37831-6064

${ }^{4}$ Department of Chemical Engineering, Kansas State University, Manhattan, KS, 66506

\begin{abstract}
In the present study, the type and densities of defects in AlN crystals grown on $6 \mathrm{H}-\mathrm{SiC}$ seeds by the sublimation-recombination method were assessed. The positions of the defects in AlN were first identified by defect selective etching (DSE) in molten $\mathrm{NaOH}-\mathrm{KOH}$ at $400{ }^{\circ} \mathrm{C}$ for 2 minutes. Etching produced pits of three different sizes: 1.8, 2.4, and $2.9 \mu \mathrm{m}$. The etch pits were either aligned together forming a sub-grain boundary or randomly distributed. The smaller etch pits were either isolated or associated with larger etch pits. After preparing cross-sections of the pits by the focused ion beam (FIB) technique, transmission electron microscopy (TEM) was performed to determine the dislocation type (edge, mixed or screw) associated with a specific etch pit size. Preliminary TEM bright field and dark field imaging using different zone axes and diffraction vectors indicates an edge dislocation with a Burgers vector $1 / 3[11 \overline{2} 0]$ is associated with the smallest etch pit size.
\end{abstract}

\section{INTRODUCTION}

Aluminum nitride is a wide-band-gap semiconductor that has drawn a lot of interest in the past decade, along with other III-V nitride materials, for its applications in the short wavelength optoelectronics and high-temperature, high-power and high frequency electronics [1]. One factor inhibiting the development of nitride based solid-state devices is the lack of a native substrate for III- $\mathrm{V}$ nitride growth. In most cases sapphire has been a substrate of choice despite its large lattice mismatch with $\operatorname{AIN}\left(\mathrm{a}_{\mathrm{Al} 2 \mathrm{O} 3}=4.76 \AA\right.$; $\left.\mathrm{a}_{\mathrm{AIN}}=3.112 \AA\right)$, that results in a high density of extended and threading dislocations, which in turn reduces both the optical and electrical efficiency of the AlN [2]. By changing to homoepitaxial growth using AlN single crystal substrates, the defect densities will be drastically reduced. Thus, there is intense research worldwide to develop AlN single crystal substrates. Sublimation is currently the most successful method for growing bulk AlN single crystals. The basic method was most famously demonstrated three decades ago by Slack and McNelly [3].

Expanding the crystal size remains a major problem for bulk AlN crystal growth. One solution is to employ silicon carbide seeds, since single crystal substrates up to $100 \mathrm{~mm}$ in diameter are commercially available. This process has been the topic of several papers by our group [4-7].

Defect selective etching (DSE) in molten salts has been applied to many materials by a host of researchers [2, 8-11] to reveal dislocation densities attributed to defects (threading 
dislocations and nano-pipes). Since AlN is an anisotropic material, Al- or N-polar faces etch at different rates. Bickermann et al [12-15] performed wet $\mathrm{KOH}$ etching on a free standing AlN crystal. They reported a lack of defect etching features on as grown rhombohedral and prismatic facets as N-polar basal planes exhibited hexagonal pyramid hillocks for etching at $240^{\circ} \mathrm{C}$ and $\mathrm{Al}-$ polar basal planes produced hexagonal etch pits of uniform size. Zhuang et al [16] reported that DSE of AlN is best performed in molten $\mathrm{NaOH}-\mathrm{KOH}$ eutectic at temperatures ranging from $170^{\circ} \mathrm{C}$ to $360^{\circ} \mathrm{C}$ depending on the crystallographic face being etched: while the nitrogen-polar face is etched rapidly at $170^{\circ} \mathrm{C}$ covering the whole surface with hexagonal pyramids, the aluminum-polar face is attacked only at sufficiently higher temperatures leading to hexagonal etch pits of uniform size. Bondokov et al [17] used atomic force microscopy (AFM) and scanning electron microscopy (SEM) images to associate etch pit type to a dislocation in which they identified a screw dislocation from the observed spiral step pattern.

Detailed measurements of the geometrical parameters of pits showed that the large pits formed on screw and mixed dislocations have an inclination angle of the side walls about twice that of pits formed on the edge dislocations [18]. The direction and magnitude of Burgers vector for edge, screw, mixed and nano-pipes are given by:

$\boldsymbol{b}_{\mathrm{e}}=1 / 3<11-20>, \boldsymbol{b}_{\mathrm{e}}=\mathrm{a}, \boldsymbol{b}_{\mathrm{e}}^{2}=\mathrm{a}^{2}$

$\boldsymbol{b}_{\mathrm{m}}=1 / 3<11-23>,\left(\boldsymbol{b}_{\mathrm{m}}=\sqrt{ } \mathrm{c}^{2}+\mathrm{a}^{2}, \boldsymbol{b}_{\mathrm{m}}^{2}=3.66 \mathrm{a}^{2}\right)$

$\boldsymbol{b}_{\mathrm{s}}=[0001],\left(\boldsymbol{b}_{\mathrm{s}}=\mathrm{c}, \mathbf{b}_{\mathrm{s}}^{2}=2.66 \mathrm{a}^{2}\right)$,

$\mathrm{b}_{\text {nano }}=n \times \boldsymbol{b}_{\mathrm{s}}$ where $n=1,2, .$.

The differences in magnitude of Burgers vectors should bring about changes in shape and/or size of etch pits depending on the type of dislocation. For gallium nitride, Weyher et al [18-20] established the association between three etch pit sizes and specific types of dislocations; the largest pits formed on nano-pipes, the medium size pits formed on screw and mixed dislocations, and the smallest pits on edge type dislocations. A similar relationship was reported for $\mathrm{HCl}$ etching of $\mathrm{GaN}$ at $600^{\circ} \mathrm{C}$ [21]. On the other hand, Shiojima et al [22] found larger pits on mixed and smaller ones on edge dislocations.

The goal of the present study is to use TEM imaging (two beam condition) at different zone axes and diffraction vectors to systematically associate a particular etch pit size in bulk AlN single crystals with the specific types of defects.

\section{EXPERIMENTAL DETAILS}

The AlN crystals were grown by the sublimation- recondensation method in a resistivelyheated graphite furnace. The source material was AlN powder originally containing less than 1 wt $\%$ oxygen and 0.06 wt \% carbon. Prior to crystal growth, the AlN souce powder was sintered $1900{ }^{\circ} \mathrm{C}$ for $4 \mathrm{~h}$, to lower the oxygen concentration to less than $0.1 \mathrm{wt} \%$. Si-face, $6 \mathrm{H}-\mathrm{SiC}(0001)$ with a $3.5^{\circ}$ misorientation toward the $(11 \overline{2} 0)$ was employed as the substrate. The temperature of the substrate was $5-10^{\circ} \mathrm{C}$ lower than the source $\left(1830^{\circ} \mathrm{C}\right)$ materials and the crystal was grown for 100 hours. A thick AIN layer of thickness $0.75 \mathrm{~mm}$ was produced. Such thickness is far in excess of those obtained using common epitaxial growth techniques such as molecular beam epitaxy or metalorganic vapor-phase deposition. The sample was etched in a molten $\mathrm{KOH} / \mathrm{NaOH}$ eutectic alloy at $400{ }^{\circ} \mathrm{C}$ for 2 minutes.

Cross-sectional TEM specimens from selected etch pits were prepared using the focused ion beam (FIB) lift-out method [23]. A FEI Nova 200 dual beam (DB) FIB was used to prepare 
the TEM specimens. The lift-out specimens were then in-situ welded onto half copper-grids using Platinum. The specimens were analyzed using a FEI Tecnai 20 TEM and bright and dark field two beam diffraction condition imaging.

\section{RESULTS and DISCUSSION}

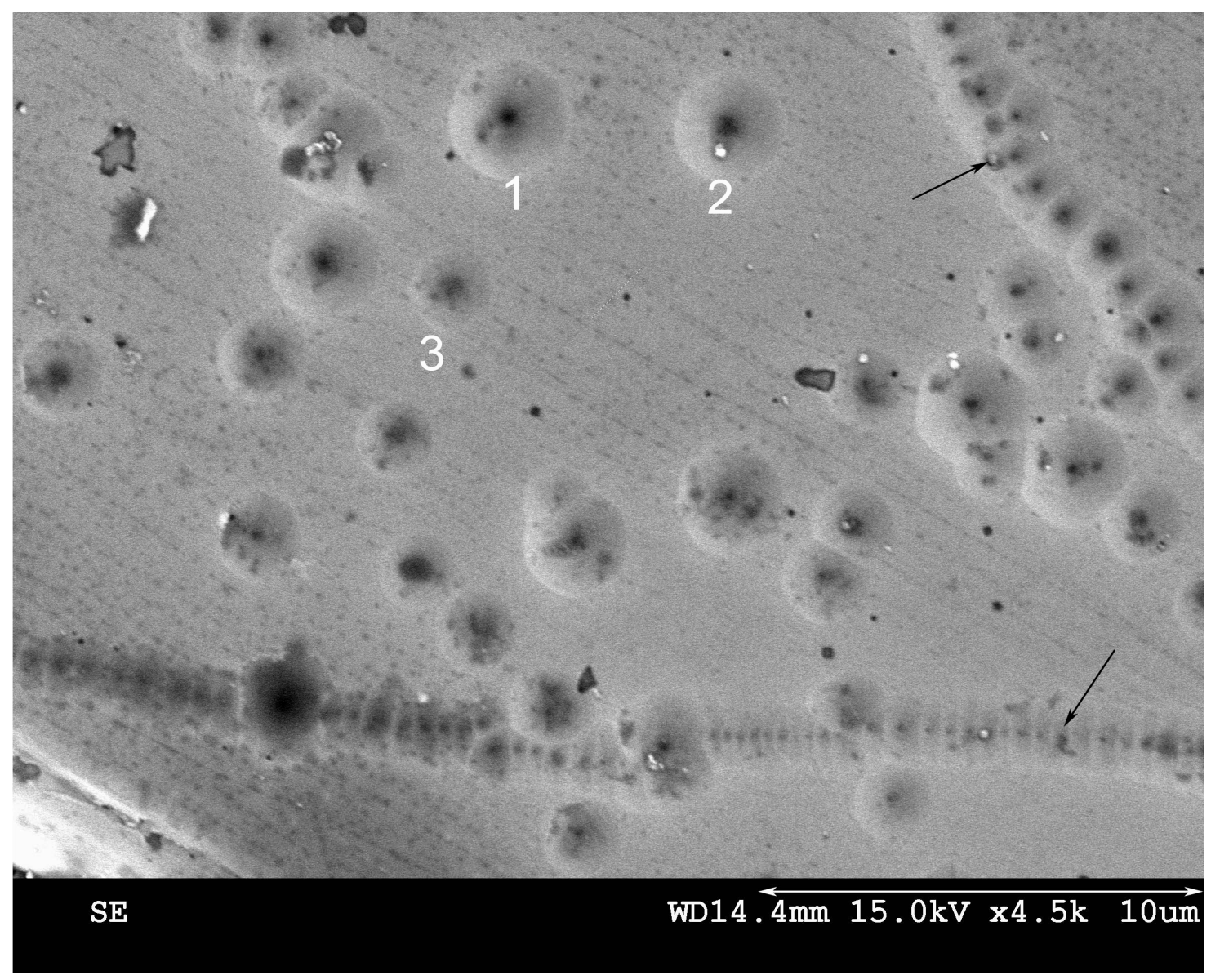

Figure 1. SEM image of as-grown aluminum polar basal plane surface after DSE at $400{ }^{\circ} \mathrm{C}$ for 2 minutes. Numbers 1, 2 and 3 refer to the etch pits of diameter size 2.9, 2.4 and $1.8 \mu \mathrm{m}$, respectively. Arrows indicate subgrain boundaries.

Hexagonal etch pits were formed on the as grown Al polar basal plane surface after DSE. Etch pits of three different diameter sizes 1.8, 2.4 and $2.9 \mu \mathrm{m}$ were revealed as shown in the SEM image in Figure 1. The etch pits of the smallest size are largest in number and are aligned mostly along sub-grain boundaries.

Figures 2 (a), (b), (c), (d) and (e) show TEM dark field images near the [2 $\overline{1} \overline{1} 0]$ or [01 $\overline{1} 0]$ zone axes formed using either $01 \overline{1} 0,0002$ or $2 \overline{1} \overline{1} 2$ diffraction vectors (i. e. g-vectors), 


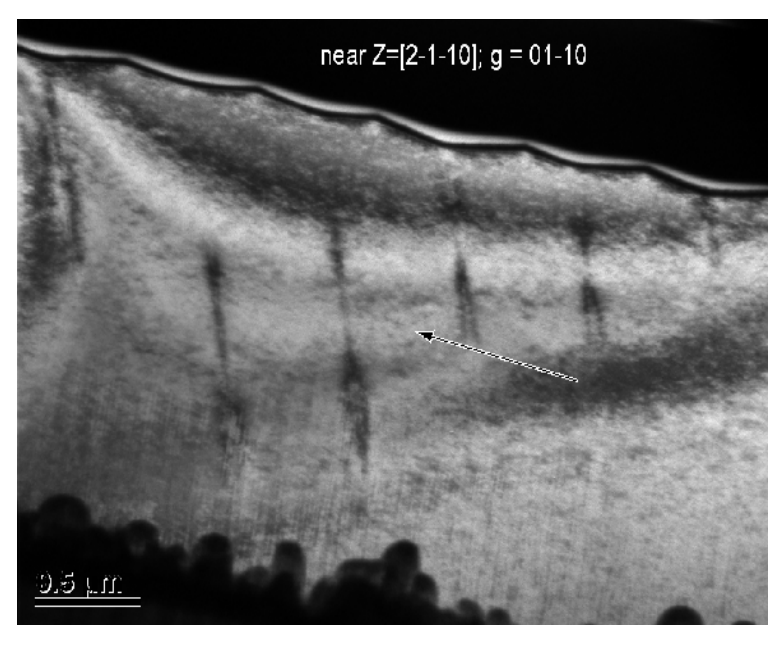

(a)

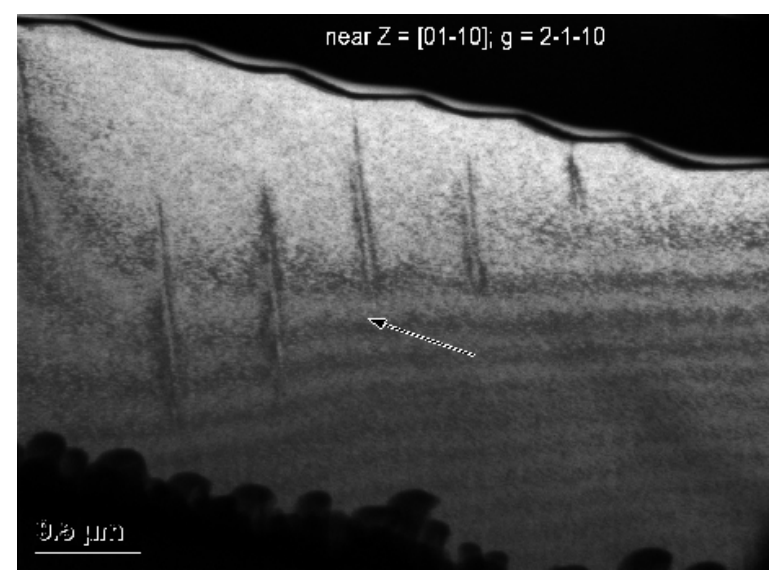

(c)

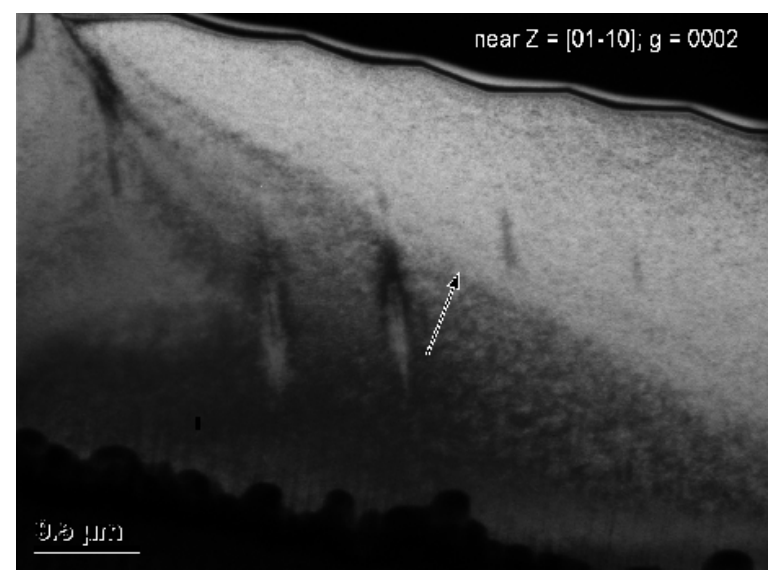

(e)

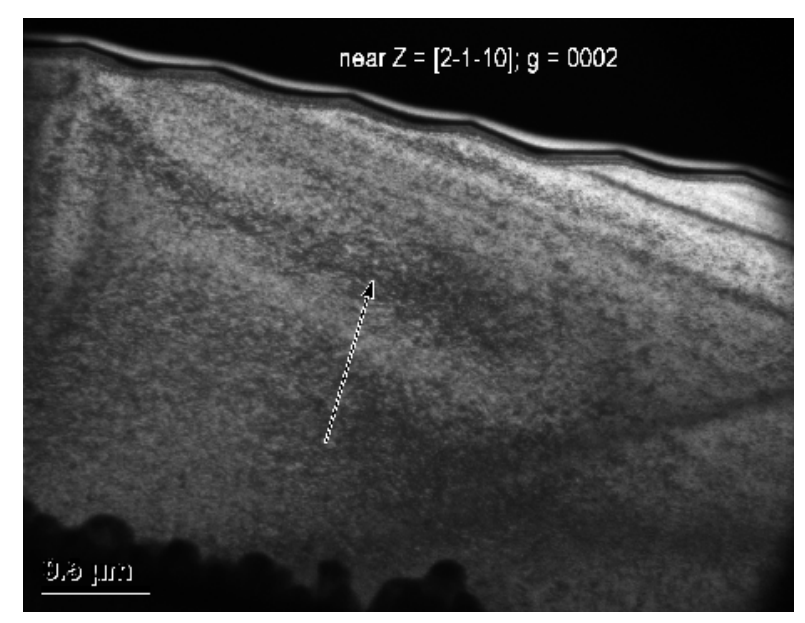

(b)

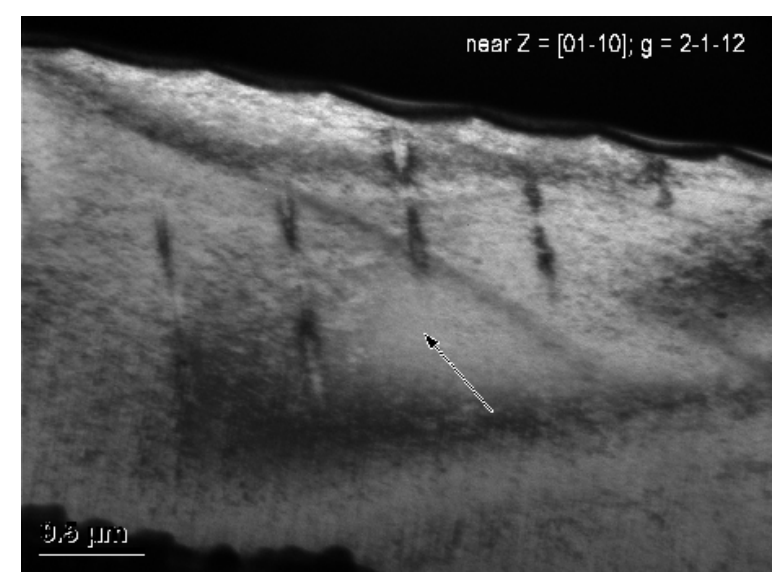

(d)

Figure 2. Cross-sectional TEM dark field images of the etched AlN (a) [2 $\overline{1} \overline{1} 0]$ zone axis, diffraction vector, $\mathrm{g}=01 \overline{1} 0$ (b) $[2 \overline{1} \overline{1} 0]$ zone axis, $g=0002$, (c) $[01 \overline{1} 0]$ zone axis, $g=2 \overline{1} \overline{1} 0$, (d) [01 $\overline{1} 0]$ zone axis, $g=2 \overline{1} \overline{1} 2$ and (e) [01 $\overline{1} 0]$ zone axis, $\mathrm{g}=0002$. 
respectively, under the weak beam condition. Figures 2 (a), (c) and (d) identify dislocations associated with a row of closely-spaced etch pits of size $1.8 \mu \mathrm{m}$ (i. e. one dislocation is associated with each etch pit). Figures 2 (b) and (e) indicate the near disappearance of the dislocations for $g=0002$ diffraction vector for both [2 $\overline{1} \overline{1} 0]$ or [01 $\overline{1} 0$ ] zone axes. Results from the two beam condition images using multiple combinations of zone axes and $g$ vectors are summarized in Table I. Using $g \cdot b=0$ criteria, the direction of the Burgers vector of the dislocation, $b$, is estimated as $[11 \overline{2} 0]$. This method provides the direction of the Burgers vector, not the magnitude, but once the direction is known, the magnitude is unique. From reference [24] the Burgers vector of this dislocation is $1 / 3[11 \overline{2} 0]$. Thus, it is confirmed that the dislocations associated with the smallest size etch pits (i. e. diameter $\sim 1.8 \mu \mathrm{m}$ ) are edge type. Since these edge dislocations are parallel to the [0001] crystal growth direction, they are located in the prism plane (i. e. $\{01 \overline{1} 0\}$ plane). The dislocation density is estimated approximately as $2.0 \times 10^{7}$ per $\mathrm{cm}^{2}$. Since the density of the smallest etch pits is much higher compared to the that of etch pits of larger size, it can be concluded dislocations present are predominately edge type. Further study is underway to identify the type of dislocations associated with the etch pits of larger size.

Table 1. Burgers vector, zone axis, $\mathrm{g}$ vector, dislocation contrast, and $\mathrm{g} \cdot \mathrm{b}$ used in this analysis.

\begin{tabular}{|c|c|c|c|c|}
\hline Burgers Vector, $\boldsymbol{b}$ ( $\left.\mathbf{x}^{1 / 3}\right)$ & Zone Axis & $\boldsymbol{g}$ Vector & Dislocation Contrast & $g \cdot b$ \\
\hline $\begin{array}{l} \pm[11-20] \\
\pm[-12-10] \\
\pm[11-20] \\
\pm[-12-10]\end{array}$ & $\begin{array}{l}{[2-1-10]} \\
{[2-1-10]}\end{array}$ & $\begin{array}{l}01-10 \\
0002\end{array}$ & $\begin{array}{l}\text { visible } \\
\text { invisible }\end{array}$ & $\begin{array}{l} \pm 1 \\
\pm 1 \\
0 \\
0\end{array}$ \\
\hline $\begin{array}{l} \pm[11-20] \\
\pm[-12-10] \\
\pm[11-20] \\
\pm[-12-10] \\
\pm[11-20] \\
\pm[-12-10]\end{array}$ & $\begin{array}{l}\text { [01-10] } \\
{[01-10]} \\
{[01-10]}\end{array}$ & $\begin{array}{l}0002 \\
2-1-12 \\
2-1-10\end{array}$ & $\begin{array}{l}\text { residual contrast } \\
\text { (partially visible) } \\
\text { visible } \\
\text { visible }\end{array}$ & $\begin{array}{l}0 \\
0 \\
\pm 1 \\
\mathbb{F}_{1} \\
\pm 1 \\
\mathbb{F}_{1}\end{array}$ \\
\hline
\end{tabular}

\section{CONCLUSIONS}

Preliminary TEM bright field and dark field study was performed to assess the type and densities of defects in AlN crystals grown on $6 \mathrm{H}-\mathrm{SiC}$ by the sublimation-recombination method. DSE in molten $\mathrm{NaOH}-\mathrm{KOH}$ at $400{ }^{\circ} \mathrm{C}$ for 2 minutes was used to identify the nature and positions of the defects in AlN crystal. Three different group of etch pits with sizes 1.8, 2.4 and $2.9 \mu \mathrm{m}$ were identified. The etch pits were either aligned along a sub-grain boundary or randomly distributed. The smaller etch pits were either isolated or associated with larger etch pits. An edge dislocation with a Burgers vector $1 / 3[11 \overline{2} 0]$ is associated with the etch pit of size $1.8 \mu \mathrm{m}$ using TEM dark field images with different zone axes and diffraction vectors. 


\section{ACKNOWLEDGMENT}

This work was supported by the NSF grant \#DMR 0408774 and \# DMR0515858. TEM work was carried out at the SHaRE User Facility at Oak Ridge National Laboratory, which is sponsored by the Division of Scientific User Facilities, Office of Science, U. S. Department of Energy.

\section{REFERENCES}

1. J. C. Rojo, L. J. Schowalter, G. Slack, K. Morgan, J. Barani, S. Schujman, S. Biswas, B. Raghothamachar, M. Dudley, M. Shur, R. Gaska, N. M. Johnson, and M. Kneissl, Mat. Res. Soc. Symp. Proc. 722, K1.1 (2002).

2. L. Liu and J. H. Edgar, Mater. Sci. Eng. R 37, 61 (2002)

3. G. A. Slack and T.F. McNelly, J. Cryst. Growth 34, 263 (1976).

4. L. Liu, B. Liu, J.H. Edgar, S. Rajasingam, and M. Kuball, J. Appl. Phys. 925183 (2002)

5. J.H. Edgar, L. Liu, B. Liu, D. Zhuang, J. Chaudhuri, M, Kuball, and S. Rajasingam, J. Cryst. Growth 246, 187 (2002).

6. P.Lu, J.H. Edgar, R.G. Lee, and J. Chaudhuri, J. Cryst. Growth 300336 (2007).

7. P. Lu, J.H. Edgar, C. Cao, K. Hohn, R. Dalmau, R. Schlesser, and Z. Sitar, submitted to J. Cryst. Growth.

8. L. J. Schowalter, G. A. Slack, J. B. Whitlock, K. Morgan, S. B. Schujman, B. Raghothamachar, M. Dudley, and K. R. Evans, phys. stat. sol. (c) 0, 1997 (2003).

9. K. Sangwal, Etching of Crystals: Theory, Experiment and Applications (North-Holland, Amsterdam, 1987) pp. 87-160.

10. J.L. Weyher, R. Fornari, T. Goeroeg, J.J. Kelly, and B. Erne, J. Cryst. Growth 141, 57 (1994).

11. J. L. Weyher, G. Kamler, G. Nowak, J. Borysiuk, B. Lucznik, M. Krysko, I. Grzegory, and S. Porowski, J. Cryst. Growth 281, 135 (2005).

12. M. Bickermann, S. Schmidt, B. M. Epelbaum, P. Heimann, S. Nagata, and A. Winnacker, J. Crystal Growth 300, 299 (2006).

13. M. Bickermann, B.M. Epelbaum, and A. Winnacker, J. Cryst. Growth 269, 432 (2004).

14. B. M. Epelbaum, M. Bickermann, and A. Winnacker, J. Cryst. Growth 275, 479 (2005).

15. B. M. Epelbaum, C. Seitz, A. Magerl, M. Bickermann, and A. Winnacker, J. Cryst. Growth 265, 577 (2004).

16. D. Zhuang and J. H. Edgar, Mater. Sci. Eng. R 48, 1 (2005).

17. R T. Bondokov, K E. Morgan, R Shetty, W Liu, G A. Slack, M Goorsky, and L J. Schowalter, (Mater. Res. Soc. Symp. Proc. 892, Pittsburgh, PA, 2006) FF30-03.1.

18. J. L. Weyher, Superlatt. Microstruc 40279 (2006).

19. J. L. Weyher and L. Macht, Eur. Phys. J. Appl. Phys. 27, 37 (2004).

20. J. L.Weyher, P.D. Brown, J.L. Rouviere, T.Wosinski, A.R.A. Zauner, and I. Grzegory, J. Cryst. Growth 210, 151 (2000).

21. T. Hino, S. Tomiya, T. Miyajima, K. Yanashima, S. Hashimoto, and M. Ikeda, Appl. Phys. Lett. 76, 3421 (2000).

22. K. Shiojima, J. Vac. Sci. Technol. B 18, 37 (2000).

23. L. A.Giannuzzi, J. L. Drown, S. R. Brown, R. B. Irwin, and F.A. Stevie, Microsc. Res. Techniq. 41, 285 (1998).

24. P. Goodman and G. Lempfuhl, Acta Crystallogr., Sect. A: Cryst. Phys. Diffr., Theor. Gen. Crystallogr. 24, 339 (1968). 